\title{
A Mini-Review of Virtual Reality-Based Interventions to Promote Well-Being for People Living with Dementia and Mild Cognitive Impairment
}

\author{
Nathan M. D'Cunha ${ }^{a, b}$ Dung Nguyen ${ }^{a}$ Nenad Naumovski ${ }^{a, b} \quad$ Andrew J. McKune ${ }^{a-d}$ \\ Jane Kellett $^{a, b}$ Ekavi N. Georgousopoulou ${ }^{b, e, f} \quad$ Jane Frost $^{a} \quad$ Stephen Isbel $^{a}$ b \\ ${ }^{a}$ Faculty of Health, University of Canberra, Canberra, ACT, Australia; ${ }^{b}$ Collaborative Research in Bioactives and Biomarkers \\ (CRIBB) Group, University of Canberra, Canberra, ACT, Australia; ' Discipline of Sport and Exercise Science, Research Institute \\ for Sport and Exercise, Faculty of Health, University of Canberra, Canberra, ACT, Australia; ${ }^{\mathrm{d} D i s c i p l i n e ~ o f ~ B i o k i n e t i c s, ~ E x e r c i s e ~}$ \\ and Leisure Sciences, School of Health Sciences, University of KwaZulu-Natal, Durban, South Africa; ${ }^{e}$ Australian National \\ University Medical School, Australian National University, Canberra, ACT, Australia; ${ }^{f}$ School of Medicine, University of Notre \\ Dame, Sydney, NSW, Australia
}

\section{Keywords}

Virtual reality · Dementia - Mild cognitive impairment .

Alzheimer's disease · Feasibility studies

\begin{abstract}
Assistive technology including virtual reality and augmented reality has gained interest as a novel intervention in a range of clinical settings. This technology has the potential to provide mental stimulation, a connection to autobiographical memory through reminiscence, and enhanced quality of life (QoL) to people living with dementia (PLWD) and mild cognitive impairment (MCI). In this mini-review, we examine the available evidence from studies reporting on the potential benefits of virtual and augmented reality to provide enjoyable, leisurely activities that may promote QoL and psychological well-being and facilitate social interaction. In total, 10 studies of varying study designs and durations ( 5 min to 6 months) using virtual $(n=9)$ and augmented reality $(n=1)$ were examined in PLWD $(n=6)$ and $\mathrm{MCl}(n=$ 3), in addition to 1 study that included participants with both conditions. Overall, the virtual experiences were enjoyed by
\end{abstract}

\section{KARGER}

(c) 2019 S. Karger AG, Basel

E-Mail karger@karger.com

www.karger.com/ger the participants, improved their mood and apathy, and were preferred when compared with nonvirtual experiences. However, small sample sizes and variations in study design limit the generalizability of the results. Nevertheless, the use of virtual and augmented reality technology for PLWD and $\mathrm{MCl}$ is a novel and emerging method which may provide cognitive stimulation and improve well-being. Future research should explore the potential application of this technology to promote social interaction in both the community and aged care settings. We suggest future studies in PLWD and $\mathrm{MCl}$ assess the effects of more sustained use of virtual and augmented reality technology on psychological outcomes including QoL, apathy, and depressive symptoms, with the incorporation of physiological biomarker outcomes.

(c) 2019 S. Karger AG, Basel

\section{Introduction}

The increased prevalence of neurodegenerative conditions, such as dementia, presents a major public health burden globally, resulting in longer but not necessarily 
better lives [1]. Dementia is an umbrella term for a variety of neurodegenerative disorders that impair cognitive functions such as memory, language, and goal-directed behaviors [1] and reduce the quality of life (QoL) [2]. The discovery of new pharmacological treatments for dementia has been largely unsuccessful, bringing into focus the potential for environmental, behavioral, and lifestyle interventions to alter the disease course [3,4]. As such, there is a trend towards the investigation of nonpharmacological interventions to enhance the well-being and cognitive function of peopleliving with dementia (PLWD) [2].

PLWD present with several comorbidities and polypharmacy, highlighting the need for psychosocial approaches to manage dementia and depressive symptoms and improve QoL. Psychosocial interventions are proposed to reduce the burden of disease, particularly if introduced during the early stages of dementia [5-7]. Current psychosocial interventions for dementia include mindfulness-based activities, life review or storytelling, and music- and art-based therapies [5, 7]. These activities assist PLWD to remain engaged and they provide intellectual stimulation, prolong independence, and increase QoL. Psychosocial interventions can reduce social isolation, which is associated with more a rapid cognitive decline and a reduced QoL when compared with other modifiable risk factors for dementia [8]. Recently, the use of assistive technology has come into focus to promote the well-being and QoL of PLWD through person-centered experiences. Mild cognitive impairment (MCI) is a broad term for people between the stage of normal ageing and dementia where memory loss is present but daily activities are not impaired [9]. The use of assistive technology and the potential applications of virtual reality and augmented reality technologies have emerged in a range of medical settings, including use in PLWD and MCI [10-13].

Virtual reality is defined as a computer-simulated real or imagined 3-D environment which enables users to experience the sensation of being present in a different physical place [14]. Augmented reality enhances the experience of the real environment by superimposing "synthetic" virtual elements into the view of the physical environment, usually using a camera, smartphone, or other vision devices [10, 15]. Mixed reality is described as a broad intersection between virtual and augmented reality, which integrates 3-D holograms into the real environment [15]. The level of immersion across virtual, augmented, and mixed reality differs depending on the equipment and technology used, ranging from $360^{\circ} \mathrm{im}-$ mersive virtual reality environments delivered by head- mounted displays or high-quality screens within a closed setting to augmented reality graphics provided on a smartphone screen. Based on the immersion level, categorization of the technology has been defined as nonimmersive, semi-immersive, and fully immersive [10]. However, all forms of this technology include an interactive component and may also feature interactive computer-based cognitive training (ICT), which involves decision-making and learning within the virtual environment.

Virtual and augmented reality may have a wide range of applications for PLWD and MCI. Perhaps the most well-known application of virtual reality in this setting is as a tool to enhance clinicians' and carers' understanding and attitudes towards the experiences of PLWD through enabling them to experience what it is like to live with dementia $[10,16]$. Recently, virtual and augmented reality for PLWD has been under investigation as a cognitive assessment and diagnostic tool and in the promotion of physical activity $[10,17]$ and fall prevention $[18,19]$. In 2015 , a study by García-Betances et al. [10] indicated that virtual and augmented reality technology interventions for PLWD lacked high levels of immersion and interaction and that future virtual reality environments should be tailored to the needs of PLWD and their symptoms. Moreover, the authors recommended that PLWD would benefit from greater accessibility to this technology in their homes and residential aged care communities (e.g., wearable headsets and 3-D smart televisions). However, to date, an in-depth analysis of the potential for virtual and augmented reality to provide enjoyable, leisurely activities that may promote QoL and psychological wellbeing and facilitate social interaction has not been conducted. This mini-review aimed to examine the results from feasibility studies and controlled trials of virtual and augmented reality in PLWD and MCI on well-being and QoL and whether the participants enjoyed the experience. In addition, we will comment on the safety and efficacy of the current state of virtual and augmented reality technology and the future directions for this area of research.

\section{Methods}

In October 2018, a nonsystematic literature search was performed using the PubMed and Google Scholar electronic databases to identify papers with the following search strategy: "virtual reality" or "augmented reality" and "dementia." Articles of interest to this mini-review 
were required to be peer reviewed, published in the year 2000 or after to incorporate more recent technology, and published in English. Eligible articles were required to:

1. Include participants with a diagnosed form of dementia, MCI, or cognitive impairment indicated using a validated cognitive screening measure such as the Mini-Mental State Examination (MMSE) or the Clinical Dementia Rating (CDR) scale.

2. Examine the effects of nonimmersive, semi-immersive, and/or fully immersive virtual, augmented, or mixed reality interventions using head-mounted devices, or virtual environments, on participants' QoL, depressive symptoms, social interaction, enjoyment, and acceptability.

\section{Results}

In total, 10 articles were identified and synthesized in this mini-review. Nine articles used virtual reality and/or virtual environments [20-28], while 1 article using augmented reality was located [15]. Seven immersive virtual experiences [20,21, 24-28], 1 semi-immersive study [15], and 2 nonimmersive studies [22, 23] were included. PLWD were participants in 6 of the studies $[15,21,22,25$, 26, 28], 3 involved people with MCI [20, 23, 27], and 1 study included both PLWD and MCI [24]. The number of reports of side effects of adverse events was relatively low across the studies. Reported side effects included confusion $(n=3)[26,28]$, discomfort associated with the head-mounted device $(n=2)[15,20]$, sadness due to memories stimulated during the experience $(n=1)$ [28], tiredness $(n=1)$ [20], and difficulty with the technology $(n=1)$ [15].Results were organized into the following 3 broad categories: cognitive training, reminiscence, and therapeutic, which included exercise interventions. The study designs, sample sizes, outcome measures, and results are presented in Table 1.

\section{Cognitive Training Using Virtual and Augmented Reality}

Cognitive training is commonly applied as a method of providing stimulation to different areas of the brain, and it is regarded as a promising, nonpharmacological preventative intervention in several different populations $[29,30]$. This type of training for PLWD usually involves the guided practice of a set of standardized tasks to exercise the brain across various cognitive domains including processing speed, attention, and memory [31]. Several studies have sought to examine the effects of cognitive training using virtual reality technology on people with cognitive decline. An early study using ICT examined whether the technology could promote cognitive functioning in people with Alzheimer's disease (AD) $(n=9)$ compared to individuals with major depressive disorder $(n=9)$ and an age-matched healthy control group $(n=$ 10) [22]. In that study by Hofmann et al. [22], ICT was defined as including interactive digital photographs of the participants' real social and local environment and enabled a total of 120 decisions within the interface. Using a series of photographs illustrating a shopping route on a computer touch screen (a nonimmersive form of virtual reality), participants were asked to complete a series of tasks including route navigation and a free recall task. The findings of the study indicated that the participants in the $\mathrm{AD}$ group performed worse at baseline testing in all testing variables compared to other groups $(p<0.001)$. However, after 12 sessions of interactive cognitive training, the participants in the $\mathrm{AD}$ group had a substantial reduction in mistakes while the other groups performed similarly, suggesting that interactive cognitive training could be suitable for PLWD. Self-reported feedback revealed that participants in the $\mathrm{AD}$ group liked the training more, and it indicated that they could apply this training to assist them in real-life situations.

More recently, virtual reality memory training demonstrated effectiveness in improving memory functions in older people with MCI [27]. In a 6-month randomized controlled trial $(n=36)$, the intervention group received immersive computer-generated virtual reality memory training through a head-mounted display using a combination of auditory (music) and visual stimuli to create a virtual environment and participants navigated the virtual surroundings using a joystick. The control group received a musical therapy intervention [27]. The primary outcome measure in the study was the MMSE, a commonly used screening tool for cognitive impairment. Other aspects of cognition function were also assessed including attention, and verbal fluency through navigating the environment, learning routes, and remembering objects. After a period of 36 sessions over a 3-month training period, the intervention group showed improvements in the MMSE ( $p=0.014)$, with maintenance of the benefits following a 3-month booster phase of 24 sessions ( $p=0.044)$, while the control group MMSE scores decreased ( $p=0.001$ and $p=0.003$, respectively) compared to baseline. Other improvements were also observed, particularly in digit span forward and verbal story recall (all $p<0.05)$. Depressive symptoms measured using the Geriatric Depression Scale decreased after the initial 
Table 1. Data summary of studies

\begin{tabular}{|c|c|c|c|c|c|c|c|}
\hline $\begin{array}{l}\text { Study } \\
\text { (Country) }\end{array}$ & Design & Sample size & $\begin{array}{l}\text { Type and focus } \\
\text { feature }\end{array}$ & Intervention & Measures & Results & Conclusion \\
\hline $\begin{array}{l}\text { Aruanno } \\
\text { and Garzotto } \\
{[15] \text { (Italy) }}\end{array}$ & $\begin{array}{l}\text { Mixed } \\
\text { methods }\end{array}$ & $\begin{array}{l}\text { People with } \mathrm{AD} \text { : } \\
n=11(\mathrm{M}=6 \\
\mathrm{F}=5 ; \text { age: } \\
84.2 \pm 7.3 \text { years })\end{array}$ & $\begin{array}{l}\text { Semi-immersive } \\
\text { Engagement, } \\
\text { enjoyment }\end{array}$ & $\begin{array}{l}\text { Augmented reality } \\
\text { head-mounted } \\
\text { HoloLens } \\
\text { (MemHolo) finding } \\
\text { activities: } \\
\text { 1. Short-term } \\
\text { memory activity } \\
\text { 2. Memory game } \\
\text { 3. Memory game } \\
\text { with spatial mapping } \\
\text { (duration: } 15 \text { min) }\end{array}$ & $\begin{array}{l}\text { Self-report questionnaire } \\
\text { including simplified } \\
\text { System } \\
\text { Usability Scale (Likert } \\
\text { scale) } \\
\text { Observations from the } \\
\text { therapist and carer }\end{array}$ & $\begin{array}{l}\text { Participants assigned positive } \\
\text { ratings to the experience for } \\
\text { likeability, engagement, and } \\
\text { comfort; observers noted } \\
\text { difficulty using the "clicking" } \\
\text { system, and successful } \\
\text { completion of the activities } \\
\text { varied. }\end{array}$ & $\begin{array}{l}\text { The MemHolo } \\
\text { was enjoyable and } \\
\text { well accepted, } \\
\text { although } \\
\text { the technology } \\
\text { could be more } \\
\text { user friendly } \\
\text { for AD. }\end{array}$ \\
\hline $\begin{array}{l}\text { Bourrelier } \\
\text { et al. [20] } \\
\text { (France) }\end{array}$ & $\begin{array}{l}\text { Mixed } \\
\text { methods } \\
\text { cross-over }\end{array}$ & $\begin{array}{l}\text { People with MCI: } \\
n=7(\mathrm{M}=3, \mathrm{~F}=4 ; \\
\text { age: } 79.1 \pm 4.7 \text { years }) \\
\text { Healthy group: } \\
n=17(\mathrm{M}=9, \mathrm{~F}=6 ; \\
\text { age: } 76.6 \pm 5.1 \text { years })\end{array}$ & $\begin{array}{l}\text { Immersive } \\
\text { Engagement, } \\
\text { enjoyment }\end{array}$ & $\begin{array}{l}\text { Virtual environment } \\
\text { displayed on } 2 \text { large } \\
\text { screens with } \\
\text { head-mounted 3-D } \\
\text { glasses and } \\
\text { body-tracking } \\
\text { sensors: } \\
\text { 1. Implicit scenario: } \\
\text { harvesting-fruit } \\
\text { scenario } \\
\text { 2. Explicit scenario: } \\
\text { physiotherapist-led } \\
\text { exercise session } \\
\text { (duration: } 40 \text { min } \\
\text { in total) }\end{array}$ & $\begin{array}{l}\text { Interviews to assess } \\
\text { participants' feelings } \\
\text { about and relationship } \\
\text { with VR } \\
\text { Performance in the } \\
\text { scenarios }\end{array}$ & $\begin{array}{l}\text { Participants enjoyed the } \\
\text { experiences and showed a } \\
\text { good perception of the } \\
\text { elements involved. There } \\
\text { was difficulty understanding } \\
\text { the explicit session; however, } \\
\text { engagement with the } \\
\text { physiotherapist was viewed } \\
\text { as motivating and entertaining; } \\
\text { the competitive spirit was } \\
\text { higher in all of the participants } \\
\text { but slightly lower in the MCI } \\
\text { group, as were appropriate } \\
\text { movements in the implicit } \\
\text { session }(p<0.001) \text {. }\end{array}$ & $\begin{array}{l}\text { The implicit VR } \\
\text { experience was } \\
\text { preferred, and the } \\
\text { technology } \\
\text { generated } \\
\text { a sense of a } \\
\text { competitive spirit. }\end{array}$ \\
\hline $\begin{array}{l}\text { Eisapour } \\
\text { et al. [21] } \\
\text { (Canada) }\end{array}$ & $\begin{array}{l}\text { Pre and } \\
\text { post study }\end{array}$ & $\begin{array}{l}\text { People with } \\
\text { dementia: } n=6 \\
(\mathrm{M}=1, \mathrm{~F}=5 ; \\
\text { age }=86.8 \text { years })\end{array}$ & $\begin{array}{l}\text { Immersive } \\
\text { Therapeutic, } \\
\text { exergaming }\end{array}$ & $\begin{array}{l}\text { 1. Therapist-guided } \\
\text { exercise } \\
\text { 2. Immersive VR } \\
\text { farm environment } \\
\text { 3. Immersive VR } \\
\text { gym environment } \\
\text { (duration: } 1 \text { week } \\
\text { each [within } 20 \mathrm{~min} \text { ], } \\
5 \text { times/week) }\end{array}$ & $\begin{array}{l}\text { Pre and post } \\
\text { questionnaires } \\
\text { (5-point Likert scale) }\end{array}$ & $\begin{array}{l}\text { Overall levels of ease of the } \\
\text { tasks were higher in VR than } \\
\text { in the human-guided exercise } \\
(p>0.05) \text {. }\end{array}$ & $\begin{array}{l}\text { The VR } \\
\text { experiences } \\
\text { were comparable } \\
\text { to the } \\
\text { therapist-guided } \\
\text { exercise. }\end{array}$ \\
\hline $\begin{array}{l}\text { Hofmann } \\
\text { et al. [22] } \\
\text { (Germany) }\end{array}$ & $\begin{array}{l}\text { Randomized } \\
\text { controlled } \\
\text { trial }\end{array}$ & $\begin{array}{l}\text { AD group: } n=9 \\
(\mathrm{M}=2, \mathrm{~F}=7 ; \\
\text { age }=68.1 \text { years }) \\
\text { People with major } \\
\text { depressive disorder: } \\
n=9(\mathrm{M}=2, \mathrm{~F}=7 ; \\
\text { age }=67.3 \text { years }) \\
\text { Healthy controls: } \\
n=10(\mathrm{M}=3, \\
\mathrm{F}=7 ; \text { age }= \\
69.3 \text { years })\end{array}$ & $\begin{array}{l}\text { Nonimmersive } \\
\text { Cognitive } \\
\text { training } \\
\text { (spatial } \\
\text { orientation, } \\
\text { cognitive } \\
\text { flexibility, } \\
\text { long-term } \\
\text { memory) }\end{array}$ & $\begin{array}{l}\text { Interactive cognitive } \\
\text { training program } \\
\text { simulating } \\
\text { a shopping route } \\
\text { (duration: } 12 \text { weeks, } \\
3 \text { times/week) }\end{array}$ & $\begin{array}{l}\text { CDR, MMSE, } \\
\text { Trail-Making } \\
\text { Test A, Self-Rating } \\
\text { Scale }\end{array}$ & $\begin{array}{l}\text { In the AD group mistakes } \\
\text { were reduced }(p<0.044) \text { and } \\
\text { training gains were sustained, } \\
\text { while performance remained } \\
\text { consistent in the other groups. }\end{array}$ & $\begin{array}{l}\text { The task } \\
\text { performance } \\
\text { and enjoyment } \\
\text { of } \mathrm{AD} \text { group } \\
\text { improved over } \\
\text { time. }\end{array}$ \\
\hline $\begin{array}{l}\text { Man } \\
\text { et al. [23] } \\
\text { (Hong Kong) }\end{array}$ & $\begin{array}{l}\text { Randomized } \\
\text { controlled } \\
\text { trial }\end{array}$ & $\begin{array}{l}\text { People with } \\
\text { questionable } \\
\text { dementia } \\
\text { (MCI): VR group, } \\
n=20(\mathrm{M}=3, \\
\mathrm{F}=17 ; \text { age }= \\
80.3 \pm 1.21 \text { years }) \\
\text { Therapist-led } \\
\text { group: } n=24 \\
(\mathrm{M}=2, \mathrm{~F}=22 ; \\
\text { age }=80.3 \pm 1.31 \\
\text { years })\end{array}$ & $\begin{array}{l}\text { Nonimmersive } \\
\text { Cognitive } \\
\text { training } \\
\text { (episodic } \\
\text { memory) }\end{array}$ & $\begin{array}{l}\text { Nonimmersive VR } \\
\text { memory-training } \\
\text { program vs. } \\
\text { therapist-led } \\
\text { memory } \\
\text { training sessions } \\
\text { (duration: } 10 \\
\text { sessions [ } 30 \text { min], } \\
2-3 \text { times/week) }\end{array}$ & $\begin{array}{l}\text { Multifactorial Memory } \\
\text { Questionnaire, Fuld } \\
\text { Object } \\
\text { Memory Evaluation, } \\
\text { Hong Kong } \\
\text { Chinese version of } \\
\text { the Lawton } \\
\text { Instrumental Activities } \\
\text { of Daily Living }\end{array}$ & $\begin{array}{l}\text { The VR group improved in } \\
\text { all } 3 \text { FOME scores: total } \\
\text { encoding, total recall, delayed } \\
\text { recall }(p<0.05) \text { and MMQ } \\
\text { strategy }(p=0.048) \text {. }\end{array}$ & $\begin{array}{l}\text { The VR group } \\
\text { performed better } \\
\text { than the non-VR } \\
\text { group in objective } \\
\text { memory tasks. }\end{array}$ \\
\hline $\begin{array}{l}\text { Mendez } \\
\text { et al. [25] }\end{array}$ & $\begin{array}{l}\text { Mixed } \\
\text { methods }\end{array}$ & $\begin{array}{l}\text { People with } \\
\text { behavioral-variant } \\
\text { frontotemporal } \\
\text { dementia: } n=5 \\
(\mathrm{M}=2, \mathrm{~F}=3 ; \\
\text { age }=56.0 \pm 12.8 \\
\text { years })\end{array}$ & $\begin{array}{l}\text { Immersive } \\
\text { Therapeutic }\end{array}$ & $\begin{array}{l}\text { Immersive interview } \\
\text { with avatars in an } \\
\text { immersive } \\
\text { virtual environment } \\
\text { (conference table) } \\
\text { (duration: } 1 \text { session) }\end{array}$ & $\begin{array}{l}\text { Self-reported levels } \\
\text { of arousal, stress, } \\
\text { anxiety, anger, fatigue, } \\
\text { and attention } \\
\text { (Likert scale) } \\
\text { Observations of head } \\
\text { turning and analysis } \\
\text { of verbal responses } \\
\text { Heart rate }\end{array}$ & $\begin{array}{l}\text { Overall, participants were } \\
\text { more open to communicating } \\
\text { with the avatars and endorsing } \\
\text { problems related to their } \\
\text { condition compared with } \\
\text { the same interview in the } \\
\text { real world. } \\
\text { There was no difference in } \\
\text { pre and post measures on } \\
\text { the Mean Stress Symptom } \\
\text { Rating Questionnaire. }\end{array}$ & $\begin{array}{l}\text { The virtual } \\
\text { experience } \\
\text { was safe and well } \\
\text { accepted, } \\
\text { facilitating } \\
\text { an improvement } \\
\text { in } \\
\text { social-emotional } \\
\text { behavior. }\end{array}$ \\
\hline
\end{tabular}


Table 1. (continued)

\begin{tabular}{|c|c|c|c|c|c|c|c|}
\hline $\begin{array}{l}\text { Study } \\
\text { (Country) }\end{array}$ & Design & Sample size & $\begin{array}{l}\text { Type and focus } \\
\text { feature }\end{array}$ & Intervention & Measures & Results & Conclusion \\
\hline $\begin{array}{l}\text { Manera } \\
\text { et al. [24] } \\
\text { (France) }\end{array}$ & $\begin{array}{l}\text { Randomized } \\
\text { controlled } \\
\text { trial }\end{array}$ & $\begin{array}{l}\text { MCI group: } n=28 \\
(\mathrm{M}=15, \mathrm{~F}=13 ; \\
\text { age }=75 \pm 6.8 \text { years }) \\
\text { Dementia group } \\
n=29(\mathrm{M}=17, \\
\mathrm{F}=12 ; \text { age }= \\
76.3 \pm 7.2 \text { years })\end{array}$ & $\begin{array}{l}\text { Immersive } \\
\text { Cognitive } \\
\text { training } \\
\text { (attention) }\end{array}$ & $\begin{array}{l}\text { VR attention task } \\
\text { selecting } \\
\text { characters in a } \\
\text { familiar } \\
\text { location with a } \\
\text { wireless mouse } \\
\text { (duration: } 5 \text { min } \\
\text { per scene) }\end{array}$ & $\begin{array}{l}\text { Self-report questionnaire, } \\
\text { apathy (diagnostic criteria), } \\
\text { task performance }\end{array}$ & $\begin{array}{l}39 \text { participants }(68.4 \%) \\
\text { preferred the VR intervention, } \\
15(26.3 \%) \text { preferred the paper } \\
\text { condition, and } 4(5.3 \%) \\
\text { expressed no preference. } \\
\text { The MCI group had a better } \\
\text { task performance compared } \\
\text { to the AD group }(p=0.008) \text {. }\end{array}$ & $\begin{array}{l}\text { Participants } \\
\text { preferred VR } \\
\text { over paper } \\
\text { conditions, } \\
\text { suggesting that } \\
\text { VR-based } \\
\text { training can be } \\
\text { used to improve } \\
\text { adherence to } \\
\text { cognitive } \\
\text { training. }\end{array}$ \\
\hline $\begin{array}{l}\text { Moyle } \\
\text { et al. [26] } \\
\text { (Australia) }\end{array}$ & $\begin{array}{l}\text { Mixed } \\
\text { methods }\end{array}$ & $\begin{array}{l}\text { Residents with } \\
\text { dementia: } n=10 \\
(\mathrm{M}=3, \mathrm{~F}=7 ; \\
\text { age }=89 \pm 4.7 \text { years }) \\
\text { Family members: } \\
n=10 \\
\text { Care staff: } n=9\end{array}$ & $\begin{array}{l}\text { Immersive } \\
\text { Engagement, } \\
\text { enjoyment, } \\
\text { apathy }\end{array}$ & $\begin{array}{l}\text { VR forest } \\
\text { (duration: } \\
\text { 15-min session) }\end{array}$ & $\begin{array}{l}\text { Observed Emotion Rating } \\
\text { Scale, Person-Environment } \\
\text { Apathy Rating, type of } \\
\text { Engagement, semistructured } \\
\text { interviews evaluating the } \\
\text { overall experience }\end{array}$ & $\begin{array}{l}\text { Residents experienced more } \\
\text { pleasure }(p=0.008) \text {, a greater } \\
\text { level of alertness }(p<0.001) \text {, } \\
\text { and higher fear/anxiety } \\
(p=0.16)\end{array}$ & $\begin{array}{l}\text { VR forest has } \\
\text { a positive impact } \\
\text { on mood but } \\
\text { also a higher } \\
\text { level of } \\
\text { fear/anxiety. }\end{array}$ \\
\hline $\begin{array}{l}\text { Optale } \\
\text { et al. [27] } \\
\text { (Italy) }\end{array}$ & $\begin{array}{l}\text { Randomized } \\
\text { controlled } \\
\text { trial }\end{array}$ & $\begin{array}{l}\text { People with MCI: } \\
n=36(\mathrm{M}=12 \\
\mathrm{F}=24 ; \text { age }= \\
80.0 \text { years })\end{array}$ & $\begin{array}{l}\text { Immersive } \\
\text { Cognitive } \\
\text { training } \\
\text { (verbal } \\
\text { memory, } \\
\text { executive } \\
\text { functions) }\end{array}$ & $\begin{array}{l}\text { Intervention: } \\
\text { VR memory training } \\
\text { along with auditory } \\
\text { session Control: music } \\
\text { therapy (duration: } 3 \\
\text { auditory and } 3 \\
\text { VR sessions every } 2 \\
\text { weeks + } 1 \text { auditory and } \\
1 \text { VR session } \\
\text { per week in the } \\
\text { following } 3 \text { months) }\end{array}$ & $\begin{array}{l}\text { Self-report questionnaire, } \\
\text { MMSE, verbal story recall, } \\
\text { phonemic verbal fluency, } \\
\text { dual-task performance, } \\
\text { Cognitive Estimation Test, } \\
\text { Clock Drawing Test, } \\
\text { activities of daily living } \\
\text { (functional and mobility), } \\
\text { instruments of } \\
\text { daily living, Geriatric } \\
\text { Depression Scale }\end{array}$ & $\begin{array}{l}\text { The intervention group } \\
\text { improved in memory tasks } \\
(p=0.043) \text {. } \\
\text { Controls performed worse in } \\
\text { memory tasks }(p<0.001) \text {. }\end{array}$ & $\begin{array}{l}\text { Participants in } \\
\text { the intervention } \\
\text { group showed } \\
\text { improvements } \\
\text { in cognitive } \\
\text { outcomes while } \\
\text { a progressive } \\
\text { decline was } \\
\text { reported in the } \\
\text { control group. }\end{array}$ \\
\hline $\begin{array}{l}\text { Siriaraya } \\
\text { and Ang } \\
{[28](\mathrm{UK})}\end{array}$ & Qualitative & $\begin{array}{l}\sim 20 \text { residents } \\
\text { with dementia, } \\
6 \text { carers/ activity } \\
\text { facilitators, } 2 \\
\text { care managers } \\
\text { (age }=\text { NR) }\end{array}$ & $\begin{array}{l}\text { Immersive } \\
\text { Therapeutic }\end{array}$ & $\begin{array}{l}\text { Three VR prototypes: } \\
\text { reminiscence room, } \\
\text { virtual river and park } \\
\text { tours, and gardening } \\
\text { (duration: NR) }\end{array}$ & $\begin{array}{l}\text { Observations, focus } \\
\text { groups, interviews }\end{array}$ & $\begin{array}{l}\text { Three themes were identified: } \\
\text { augmenting the sense of self, } \\
\text { designing ludic experiences, } \\
\text { user interactions. }\end{array}$ & $\begin{array}{l}\text { VR created ludic } \\
\text { experiences and } \\
\text { facilitated } \\
\text { interaction for } \\
\text { people with } \\
\text { dementia. }\end{array}$ \\
\hline
\end{tabular}

Ages are presented as means \pm SD. M, males; F, females; FOME, Fuld Object Memory Evaluation; IBVE, image-based virtual environment; NR, not reported.

3 -month training period $(p=0.025)$ but not after the booster period. Higher depressive symptoms were observed in the control group after 3 months but not after the booster.

Similarly, findings were reported in another randomized controlled trial $(n=44)$ of participants with questionable dementia (indicated by the CDR scale as consistent with MCI) using nonimmersive scenario-based virtual reality memory training, while participants in the control groups underwent therapy-led non-virtual reality sessions of memory training using similar scenarios [23]. The computer-generated virtual reality experience presented 2 scenarios: firstly, a home setting with 2 bedrooms, a living room, a dining room, a kitchen, and a bathroom, and, secondly, a convenience store with several products, refrigerators, and a cashier. Participants were given verbal and written instructions and timed while navigating the scenarios using a joystick and carry- ing out specific tasks. Practice effects were observed in both groups; however, the intervention group performed better in total encoding, total recall and delayed recall in the Fuld Object Memory Evaluation and the Multifactorial Memory Questionnaire (strategy) (all $p<0.001$ ). However, only the non-virtual reality group reported improvements in the Multifactorial Memory Questionnaire (contentment).

The most recent study identified examined the use of the HoloLens (Microsoft Corp., Redmond, WA, USA) device, an augmented reality system that presents computergenerated 3-D objects in the real environment, on people with AD [15]. The authors tested 3 activities (MemHolo) which required participants to click to open objects to reveal their content and use their short-term memory to match items and progress through the scenario. Overall, participants responded that they enjoyed the virtual experience and were able to follow the instructions with assis- 
tance (when required) from a carer. Nine of the participants responded that the experience was engaging and that they would like to reuse the system. The observations from carers noted that participants had some difficulty with clicking on the objects and one participant had trouble reading the instructions due to her glasses. Interestingly, the authors conducted the study in small groups of 2-3 participants which promoted interaction and enabled participants to provide each other with suggestions. The findings from these studies suggest that virtual realitybased interventions that include cognitive training can be beneficial for PLWD and may have lasting effects.

\section{Virtual Reality and Reminiscence}

With the adoption of psychosocial interventions in dementia care, reminiscence therapy is a commonly used treatment and it has been found to improve the QoL of PLWD [32]. The intervention works on the premise that several facets of memory remain intact throughout life and could be used to enhance communication with PLWD [32]. Reminiscence therapy typically involves the discussion of past activities, events, and experiences, using memory triggers as a potential aid [32]. Virtual reality interventions could be employed to trigger autobiographical memories due to their high level of immersion and visual realism [33].

Image-based rendering technology has been effective in 2 feasibility studies using mixed virtual and augmented reality experiences in stimulating autobiographical memory in older adults with minor memory complaints [14, 33]. The same image-based rendering technique was used in an immersive study of people with MCI $(n=28)$ and dementia $(n=29)$ [24]. Image-based rendering refers to the computerized reconstruction of a real environment, in this case a location familiar to the participants in the city of Nice (France), using a set of photographs. The participants wore 3-D LCD shutter glasses while sitting 1.9 $\mathrm{m}$ from the screen and completed attention tasks using a wireless mouse involving the identification of characters among a crowd of computer-generated characters. The control condition included the same attention tasks using 2-D prints and placing a rectangle over the characters. Participants reported high levels of satisfaction with the virtual game compared to the paper version of the game. Additionally, participants who met the baseline criteria for apathy were more interested in the virtual reality condition compared to nonapathetic individuals $(\mathrm{p}=0.002)$ with 39 of the 57 participants preferring the virtual reality condition. Nine participants with MCI or dementia continued to play the game at the end of the study.

Virtual Reality Use in Dementia
A study by Siriaraya and Ang [28] conducted intriguing virtual reality mixed-method investigations $(n=20)$ using different prototypes to recreating memories and social engagement in PLWD in long-term aged care. Over 9 visits, 3 different virtual reality settings ("reminiscence room," "virtual tool," and "gardening") were tested in 2 aged care facilities, followed by semistructured interviews with care staff regarding the efficacy of the interventions. Results showed that virtual reality activities triggered reminiscence, with participants reenacting stories from memories (i.e., their gardens). Reminiscence also occurred through their interaction with virtual objects, particularly with objects of personal relevance [28]. A sense of escapism was reported among participants, with reports of "being slipped into an alternate reality" along with positive feelings. However, in 1 participant, reminiscence led to feelings of sadness while reflecting on past experiences, prompting care staff to redirect the participant back into the virtual garden. More studies are needed to assess the ability of virtual reality to facilitate reminiscence in PLWD, including studies of reminiscence therapy which provides structure and support for the participant during and after the virtual experience.

\section{Virtual Reality as a Therapeutic Tool}

The therapeutic use of virtual reality has gained popularity in recent years and it has been shown to be enjoyable and enhance the sense of control among PLWD [26]. A recent mixed-method pilot study $(n=10)$ sought to examine the effects of a 15-min interactive and immersive virtual reality forest experience on the level of engagement, apathy, and mood states of PLWD from 2 aged care facilities [26]. Quantitative data for emotions, apathy, and engagement were measured using different scales and questionnaires while semistructured interviews of staff, PLWD, and their family members were conducted to evaluate the overall experience. Positive feelings towards the virtual reality forest were reported among participants and their carers, with residents experiencing more pleasure $(p=0.008)$ and a greater level of alertness $(p<$ 0.001 ) compared to established scores for PLWD in the Observed Emotion Rating Scale but also a greater level of fear or anxiety than normal for this cohort [26]. In addition, apathy was lower during the experience $(p=0.01)$, suggesting that the participants were immersed in the virtual environment. The majority of the participants $(n=$ 6 ) enjoyed the experience, while other participants reported boredom and confusion, indicating that interventions such as this one may not be appropriate for all PLWD. In this study, there were also several limitations 
identified such as the differences in settings between the 2 facilities ("dark" vs. "light" room) as well as carer facilitation styles ("passive" vs. "active" participation).

Exergaming, the term used to describe video games that include exercise, was employed recently to test the acceptability of a virtual exercise program compared to a therapist-led program $(n=6)$ [21]. In 2 immersive virtual reality experiences, PLWD were given a set of tasks to complete for 5 days per week in either a farm or a gymnasium environment. All of the participants completed the tasks with equal satisfaction compared to the therapist-led activities, and 5 wanted to continue with the virtual reality experiences. Similarly, a 2016 study by Bourrelier et al. [20] compared people with MCI and healthy older people in 2 virtual environments using head-mounted 3-D glasses to evaluate user feelings toward 2 performance-based tasks in both implicit and explicit virtual environments [20]. The implicit virtual activity required participants to pick fruit from a tree in an orchard when it is ripe and to place it into a virtual basket 3 times for 3 min with a 1 -min break between each repetition. The explicit activity involved a physiotherapy session performing arm-pointing movements, managed by an actual physiotherapist. Participants were scored based on the number of appropriate movements at the end of both tasks. Overall, participants responded favorably to both conditions but had difficulty understanding the instructions in the explicit session despite enjoying the interactive component with the physiotherapist. A sense of a competitive spirit was also reported in the implicit session; however, this and the appropriate movements measured were slightly lower in the MCI group compared to the healthy group $(p<0.001)$.

Finally, a small study by Mendez et al. [25] examined the responses of people living with frontotemporal dementia while immersed in a virtual meeting with graphical avatars while seated at a virtual conference table compared with a real-world insight interview. All of the participants $(n=5)$ interacted and engaged with the computer-generated avatars and responded to their questions with no pre to post changes $(p>0.05)$ in the Mean Stress Symptom Rating Questionnaire. The participants were more talkative and provided more details regarding their dementia than in the real-world interview, suggesting that virtual reality may facilitate more verbal interaction and improved social-emotional behavior. These findings propose that virtual reality may have emotional and social benefits, with the potential to improve QoL by providing engaging experiences for PLWD.

\section{Discussion}

Potential Implications of Virtual Reality for PLWD

The focus of this mini-review was to examine the potential for virtual and augmented reality technologies to promote the well-being and QoL of PLWD and MCI. Most studies investigating the use of virtual reality for PLWD are small exploratory and interpretive feasibility studies; however, the findings reveal that the technology promotes well-being and is well-accepted by both PLWD and MCI. The virtual experiences improved mood and apathy and were preferred when compared with nonvirtual experiences. The reviewed studies are limited by their sample size (range: 5-57) and the use of different study designs, which makes it difficult to generalize the results. The majority of studies used varying outcome measures while none of the studies used a validated QoL questionnaire. Similarly, there were inconsistencies in the purpose of virtual and augmented reality use among people at different stages of dementia and MCI. However, overall, the studies reported high levels of interaction and immersion, revealing a considerable potential for the widespread implementation of enjoyable and engaging virtual experiences for PLWD and MCI.

The interventions and feasibility studies described in this mini-review varied. Several different interactive experiences have been described; however, most were classified as virtual reality, ranging from interactive computer-based programs using a mouse and keyboard [22] to an immersive gym environment [21]. There was also considerable heterogeneity in study duration. The study by Optale et al. [27] was both the longest (6 months) and most comprehensive study discussed and investigated a wide range of cognitive outcomes, activities of daily living, and depressive symptoms. However, the majority of studies were short and exploratory, designed to evaluate the acceptability and practicality of the technology for use with PLWD or MCI. Several other outcome measures were assessed in these studies, including apathy; however, the most common method employed was a self-report questionnaire using Likert scales. Methodological issues and confounding variables were reported across most studies, highlighting the need for future well-designed interventions to test virtual technologies for PLWD and MCI. The outcome measures were also markedly different across studies. Two studies used the MMSE as an outcome measure $[22,27]$; however, comprehensive neuropsychological assessments to measure improvements in cognitive function were not performed. Not all studies 
examined recruited participants with a formal dementia diagnosis, which may have influenced results through the inclusion of participants experiencing cognitive impairment related to depression or a physical ailment such as a urinary tract infection.

Moyle et al. [26] conducted an assessment of a shorter intervention with outcomes assessing emotion, apathy, and engagement. Future long-term studies should be designed to investigate cognitive performance, mood, and QoL. In addition, the consideration of other confounders that may affect cognitive function will improve the current understanding of individual responses to virtual and augmented reality interventions. Future research should evaluate the number of prescribed medications, the frequency and intensity of physical activity, effects on sleep patterns, and responses based on cognitive reserve and education levels.

Several characteristics of virtual reality, such as the content, the immersiveness of the intervention, and the setup, require careful consideration for PLWD. For instance, the use of visually appealing and inviting scenes (garden, forest, beach, etc.) as well as incorporating personalized scenes from memories could potentially foster enjoyment and relaxation and enhance the general wellbeing. For a higher immersion level, several additional stimuli can be included, such as music, which is useful in triggering autobiographical memory and improving QoL in PLWD [34]. Moreover, virtual reality technology has advanced to enable pseudo educational and real-life experiences which may promote QoL and cognitive function through new opportunities for learning and social engagement, particularly within aged care where PLWD may not be able to travel to exciting venues such as museums, galleries, or tourist attractions. Reenacting past activities, such as gardening [28], using virtual reality may also provide stimuli to trigger motor patterns that may promote physical activity. Recently in older people, simultaneous cognitive training and aerobic exercise (stationary bike) has been shown to improve memory and attention compared with cognitive training and aerobic exercise sequentially [35]. Therefore, virtual reality cognitive training combined with aerobic exercise may also provide benefits within a rich virtual environment.

It is essential to consider the views of the consumers of the technology, including care staff, when designing and developing virtual reality-based interventions. Not all of the participants in the reviewed studies enjoyed the virtual experiences, indicating the importance of consumer consultation prior to designing, testing, and im-

Virtual Reality Use in Dementia plementing the technology. Furthermore, individualized virtual experiences and environments may hold the most significant potential to promote the well-being of PLWD. User-centered design of a virtual reality environment has also been explored in a qualitative study $(n=52)$ involving people with MCI across 4 European countries [36]. Participants were asked for their views on an immersive screen-based multisensory room (SENSE-GARDEN) which provides individualized familiar stimuli (music, film, and scents) to promote reminiscence. People with MCI and their carers and family members responded positively toward the potential of the SENSE-GARDEN experience to encourage a sense of identity and verbal communication and expression between the people with MCI and their carers. Importantly, an onboarding or practice protocol, as in the study by Man et al. [23], is recommended, where participants are allowed to familiarize themselves with the technology. During this time, observers can identify the potential for side effects or stress associated with the technology and intervene accordingly. The study by Aruanno and Garzotto [15] also tested their MemHolo intervention in older adults first, before evaluating the acceptability of PLWD.

The study by Moyle et al. [26] reported that staff assistance and encouragement were required for PLWD to engage with their virtual forest intervention, highlighting the potential for virtual reality to be resource heavy due to the need to focus on one resident at a time. However, other studies noted that the technology facilitated interaction and discussion, with one study reporting that residents assisted each other with using the technology [15]. It will be important for future studies to take into consideration the negative social implications surrounding the technological applications of virtual reality in health care settings such as increasing social withdrawal and addictive behaviors, and issues surrounding one-onone supervision by care staff. This limitation may be ameliorated through the implementation of virtual reality and virtual environments as group activities. However, care staff interviewed in the study by Siriaraya and Ang [28] were sceptical, believing that PLWD may need to process the information without additional exposure to social information [28]. Therefore, specifically designed interactive and social components of virtual environments need to be developed, including group-based, facilitated discussion while using the technology [11]. Recent pilot data has shown that group-based virtual reality can be used safely to provide older people in aged care settings with positive experiences from visual stim- 
uli based in foreign countries and museums in combination with staff-led discussion [11]. Such activities could be combined with life-story work and reminiscence therapy to enhance person-centered care with the use of technology [37, 38].

Further empirical testing should be orientated to investigate the different effects of virtual and augmented reality on different stages of dementia. The use of virtual reality for people living with severe dementia has yet to be tested and may hold promise for reminiscence, relaxation, and enjoyment. Currently, most virtual reality studies have focused on individuals with MCI or earlystage $\mathrm{AD}$, suggesting that virtual reality-based technology could be more useful as a training and rehabilitation tool for these individuals, potentially slowing cognitive decline. Given the prevalence of agitated behaviors and anxiety among patients on the more severe end of dementia, virtual reality could possibly assist in reducing stress levels and promote feelings of relaxation, particularly if use of the technology is relatively simple and safety screening is done prior to using. The use of exposure therapy using virtual reality has been successfully implemented in the treatment of stress and anxiety disorders [39]. Instead of being exposed to the real world, participants can potentially experience the same anxiety-provoking scenarios in a safer and more controlled setting. Yet, how these scenarios could be applied to PLWD and MCI is yet to be explored.

Overall, a small number of nonthreatening side effects were reported in the studies examined, including confusion and difficulty associated with using the technology. As virtual reality technology becomes more realistic and immersive, simulator sickness [40] (vertigo, dizziness, nausea, vomiting, and headaches) may pose health risks for users, especially in the case of Lewy body dementia, which may induce hallucinations and balance problems. Other health concerns to consider with virtual reality include eye strain, anxiety (due to its immersive nature), and the possibility that novel immersive experiences may stimulate sadness, such as reported in the study by Siriaraya and Ang [28]. A potential limitation of virtual reality delivered with head-mounted devices is the possibility of discomfort and agitation associated with wearing the technology. For example, the studies by Bourrelier et al. [20] and Aruanno and Garzotto [15] reported that participants who wear glasses in daily life were bothered by the head-mounted devices during the experience. With more widespread implementation of the technology, it may also be prudent to consider the possibility that equipment may be unintentionally damaged in aged care set- tings. Therefore, consideration must also be made regarding storage and the safe return of equipment to ensure the sustainability of virtual reality programs over time.

A neurological and physiological perspective is also required to understand the long-term effects of virtual reality in PLWD as the lack of mental map formation in hippocampus regions has been observed in rodents engaging in virtual reality [41]. The hippocampus is associated with formation of memories, and impaired function is linked to several forms of dementia including AD. Therefore, future research could also benefit from the inclusion of more sensitive noninvasive physiological measures such as saliva analysis (salivary cortisol and salivary a-amylase), blood pressure, and heart rate variability to examine changes in biomarkers of stress. In addition, the application of virtual reality as a fall prevention tool for PLWD requires further investigation [18]. Delivery of fall prevention training using sensorbased balanced training is well accepted by people with MCI and $\mathrm{AD}[19,42]$ and may be enhanced through immersive virtual experiences using head-mounted devices. Cognitive training delivered on a tablet while cycling on a stationary bike (neuro-exergaming) has been shown to promote executive functioning [43], indicating that benefits may be derived from specifically designed multicomponent and multidomain immersive experiences.

\section{Conclusion}

Virtual, mixed, and augmented reality interventions are becoming more accessible and they are an interesting and emerging method to potentially enhance cognitive function and stimulate autobiographical memory, as well as to promote reminiscence and potentially QoL. The findings of this mini-review offer an overview of the current feasibility studies in this area for PLWD and MCI and a glimpse toward the potential applications of this technology in the future to promote well-being. As virtual reality technology advances, longer, hypothesis-testing trials inclusive of group-facilitated interaction and specifically designed immersive virtual environments will be essential to encourage the use of the technology for PLWD and MCI, carers, and aged care communities. A combination of neuropsychological testing and physiological feedback will also be beneficial in understanding the effects of virtual and augmented reality on PLWD and MCI. 


\section{Acknowledgement}

Nathan M. D'Cunha is supported by a Dementia Australia Research Foundation PhD scholarship.

\section{Statement of Ethics}

The authors have no ethical conflicts to disclose.

\section{Disclosure Statement}

The authors have no conflicts of interest to declare.

\section{Funding Sources}

The authors have no funding sources to disclose.

\section{Author Contributions}

N.M.D., N.N., and S.I. designed this study and devised the research questions. N.M.D. and D.N. drafted this paper and carried out the literature review and data extraction. N.N., A.J.M., E.N.G., J.K., J.F., and S.I. contributed to the writing and provided critical feedback. N.M.D. was in charge of editing, reviewing, and formatting the final version of this paper. All of the authors read and contributed to this work.

\section{References}

1 World Health Organization. Dementia: key facts. Geneva: World Health Organization; 2018.

2 Cooper C, Mukadam N, Katona C, Lyketsos CG, Ames D, Rabins P, et al.; World Federation of Biological Psychiatry - Old Age Taskforce. Systematic review of the effectiveness of non-pharmacological interventions to improve quality of life of people with dementia. Int Psychogeriatr. 2012 Jun;24(6):856-70.

3 D'Cunha NM, Georgousopoulou EN, Dadigamuwage L, Kellett J, Panagiotakos DB, Thomas J, et al. Effect of long-term nutraceutical and dietary supplement use on cognition in the elderly: a 10-year systematic review of randomised controlled trials. Br J Nutr. 2018 Feb;119(3):280-98.

4 Abraha I, Rimland JM, Trotta FM, Dell'Aquila G, Cruz-Jentoft A, Petrovic M, et al. Systematic review of systematic reviews of non-pharmacological interventions to treat behavioural disturbances in older patients with dementia. The SENATOR-OnTop series. BMJ Open. 2017 Mar;7(3):e012759.

5 Patel B, Perera M, Pendleton J, Richman A, Majumdar B. Psychosocial interventions for dementia: from evidence to practice. Adv Psychiatr Treat. 2014;20(5):340-9.

6 Ballard C, Corbett A, Orrell M, Williams G, Moniz-Cook E, Romeo R, et al. Impact of person-centred care training and person-centred activities on quality of life, agitation, and antipsychotic use in people with dementia living in nursing homes: A cluster-randomised controlled trial. PLoS Med. 2018 Feb; 15(2): e1002500

7 McDermott O, Charlesworth G, Hogervorst E, Stoner C, Moniz-Cook E, Spector A, et al. Psychosocial interventions for people with dementia: a synthesis of systematic reviews. Aging Ment Health. DOI: 10.1080/13607863.2017.1423031.

8 Kuiper JS, Zuidersma M, Oude Voshaar RC, Zuidema SU, van den Heuvel ER, Stolk RP, et al. Social relationships and risk of dementia: a systematic review and meta-analysis of longitudinal cohort studies. Ageing Res Rev. 2015 Jul;22:39-57.

9 Cooper C, Sommerlad A, Lyketsos CG, Livingston G. Modifiable predictors of dementia in mild cognitive impairment: a systematic review and meta-analysis. Am J Psychiatry. 2015 Apr;172(4):323-34.

10 García-Betances RI, Arredondo Waldmeyer MT, Fico G, Cabrera-Umpiérrez MF. A succinct overview of virtual reality technology use in Alzheimer's disease. Front Aging Neurosci. 2015 May;7:80-80.

11 Gaspar P, Westberg K, Baker A, Dunlap T, Nordlinger K. What are the QOL outcomes of a group virtual reality experience for assisted living and independent living residents? Innov Aging. 2018;2:1016

12 Maggio MG, Maresca G, De Luca R, Stagnitti MC, Porcari B, Ferrera MC, et al. The Growing Use of Virtual Reality in Cognitive Rehabilitation: Fact, Fake or Vision? A Scoping Review. J Natl Med Assoc. 2019 Feb;S0027-9684(18)30346-8.

13 Liddle J, Smith SJ. Intelligent Assistive Technology for people living with dementia is a rapidly growing and changing area requiring clinical consideration. Aust Occup Ther J. 2017 Dec;64(6):510-1.

14 Benoit M, Guerchouche R, Petit PD, Chapoulie E, Manera V, Chaurasia G, et al. Is it possible to use highly realistic virtual reality in the elderly? A feasibility study with image-based rendering. Neuropsychiatr Dis Treat. 2015 Mar;11:557-63

15 Aruanno B, Garzotto F. MemHolo: mixed reality experiences for subjects with Alzheimer's disease: Proceedings of the 12th Biannual Conference on Italian SIGCHI Chapter (CHItaly '17); Cagliari; 2017.

16 Gilmartin-Thomas JF, McNeil J, Powell A, Malone DT, Wolfe R, Larson IC, et al. Impact of a Virtual Dementia Experience on Medical and Pharmacy Students' Knowledge and Attitudes Toward People with Dementia: A
Controlled Study. J Alzheimers Dis. 2018; 62(2):867-76.

17 van Santen J, Dröes RM, Holstege M, Henkemans OB, van Rijn A, de Vries R, et al. Effects of Exergaming in People with Dementia: Results of a Systematic Literature Review. J Alzheimers Dis. 2018;63(2):741-60.

18 Dockx K, Alcock L, Bekkers E, Ginis P, Reelick M, Pelosin E, et al. Fall-Prone Older People's Attitudes towards the Use of Virtual Reality Technology for Fall Prevention. Gerontology. 2017;63(6):590-8.

19 Schwenk M, Sabbagh M, Lin I, Morgan P, Grewal GS, Mohler J, et al. Sensor-based balance training with motion feedback in people with mild cognitive impairment. J Rehabil Res Dev. 2016;53(6):945-58.

20 Bourrelier J, Ryard J, Dion M, Merienne F, Manckoundia P, Mourey F. Use of a virtual environment to engage motor and postural abilities in elderly subjects with and without mild cognitive impairment (MAAMI Project). IRBM. 2016;37(2):75-80

21 Eisapour M, Cao S, Domenicucci L, Boger J. Virtual reality exergames for people living with dementia based on exercise therapy best practices. Proc Hum Factors Ergon Soc Annu Meet. 2018;62(1):528-32.

22 Hofmann M, Rösler A, Schwarz W, MüllerSpahn F, Kräuchi K, Hock C, et al. Interactive computer-training as a therapeutic tool in $\mathrm{Al}$ zheimer's disease. Compr Psychiatry. 2003 May-Jun;44(3):213-9.

23 Man DW, Chung JC, Lee GY. Evaluation of a virtual reality-based memory training programme for Hong Kong Chinese older adults with questionable dementia: a pilot study. Int J Geriatr Psychiatry. 2012 May;27(5): $513-20$.

24 Manera V, Chapoulie E, Bourgeois J, Guerchouche R, David R, Ondrej J, et al. A Feasibility Study with Image-Based Rendered Virtual Reality in Patients with Mild Cognitive Impairment and Dementia. PLoS One. 2016 Mar; 11(3):e0151487. 
25 Mendez MF, Joshi A, Jimenez E. Virtual reality for the assessment of frontotemporal dementia, a feasibility study. Disabil Rehabil Assist Technol. 2015 Mar;10(2):160-4.

26 Moyle W, Jones C, Dwan T, Petrovich T. Effectiveness of a Virtual Reality Forest on People With Dementia: A Mixed Methods Pilot Study. Gerontologist. 2018 May;58(3):478-87.

27 Optale G, Urgesi C, Busato V, Marin S, Piron L, Priftis K, et al. Controlling memory impairment in elderly adults using virtual reality memory training: a randomized controlled pilot study. Neurorehabil Neural Repair. 2010 May;24(4):348-57.

28 Siriaraya P, Ang CS. Recreating living experiences from past memories through virtual worlds for people with dementia: Proceedings of the SIGCHI Conference on Human Factors in Computing Systems. Toronto, Ontario, Canada, ACM, 2014, pp 3977-3986.

29 Rosenberg-Lee M, Iuculano T, Bae SR, Richardson J, Qin S, Jolles D, et al. Short-term cognitive training recapitulates hippocampal functional changes associated with one year of longitudinal skill development. Trends Neurosci. 2018;10:19-29.

30 Wassenaar A, Rood P, Boelen D, Schoonhoven L, Pickkers P, van den Boogaard M. Feasibility of Cognitive Training in Critically Ill $\mathrm{Pa}$ tients: A Pilot Study. Am J Crit Care. 2018 Mar;27(2):124-35.

31 Bahar-Fuchs A, Martyr A, Goh AM, Sabates J, Clare L. Cognitive training for people with mild to moderate dementia. Cochrane Data- base Syst Rev. DOI: 10.1002/14651858. CD013069.

32 Woods B, O'Philbin L, Farrell EM, Spector $\mathrm{AE}$, Orrell M. Reminiscence therapy for dementia. Cochrane Database Syst Rev. 2018 Mar;3:CD001120.

33 Chapoulie E, Guerchouche R, Petit P, Chaurasia G, Robert P, Drettakis G: Reminiscence therapy using image-based rendering in VR: Proceedings of the IEEE Virtual Reality Conference; Minneapolis (MI): IEEE Virtual Reality; 2014.

34 Vink A, Hanser S. Music-Based Therapeutic Interventions for People with Dementia: A Mini-Review. Medicines (Basel). 2018 Oct; $5(4): 5$.

35 McEwen SC, Siddarth P, Abedelsater B, Kim Y, Mui W, Wu P, et al. Simultaneous Aerobic Exercise and Memory Training Program in Older Adults with Subjective Memory Impairments. J Alzheimers Dis. 2018;62(2):795806.

36 Goodall G, Ciobanu I, Broekx R, Sørgaard J, Anghelache I, Anghelache-Tutulan C, et al. Using Adaptive Immersive Environments to Stimulate Emotional Expression and Connection in Dementia Care: Insights from User Perspectives towards SENSE-GARDEN: The Fourth International Conference on Human and Social Analytics. Venice, Italy, 2018

37 Doran C, Noonan M, Doody O: Life-story work in long-term care facilities for older people: an integrative review. J Clin Nurs. 2019 Apr;28(7);1070-84.
38 Syed Elias SM, Neville C, Scott T. The effectiveness of group reminiscence therapy for loneliness, anxiety and depression in older adults in long-term care: a systematic review. Geriatr Nurs. 2015 Sep-Oct;36(5):37280.

39 Hartanto D, Kampmann IL, Morina N, Emmelkamp PG, Neerincx MA, Brinkman WP. Controlling social stress in virtual reality environments. PLoS One. 2014 Mar;9(3): e92804.

40 Tyrrell R, Sarig-Bahat H, Williams K, Williams G, Treleaven J. Simulator sickness in patients with neck pain and vestibular pathology during virtual reality tasks. Virtual Real (Walth Cross). 2018;22(3):211-9.

41 Aghajan ZM, Acharya L, Moore JJ, Cushman JD, Vuong C, Mehta MR. Impaired spatial selectivity and intact phase precession in twodimensional virtual reality. Nat Neurosci. 2015 Jan;18(1):121-8.

42 Zhou H, Sabbagh M, Wyman R, Liebsack C, Kunik ME, Najafi B. Instrumented TrailMaking Task to Differentiate Persons with No Cognitive Impairment, Amnestic Mild Cognitive Impairment, and Alzheimer Disease: A Proof of Concept Study. Gerontology. 2017; 63(2):189-200.

43 Anderson-Hanley C, Maloney M, Barcelos N, Striegnitz K, Kramer A. Neuropsychological Benefits of Neuro-Exergaming for Older Adults: A Pilot Study of an Interactive Physical and Cognitive Exercise System (iPACES). J Aging Phys Act. 2017 Jan;25(1):73-83. 